\title{
CONEXÕES DA APRENDIZAGEM E DO CONHECIMENTO
}

\section{Connections of the Learning and the Knowledge}

\author{
Evelise Maria Labatut Portilho ${ }^{1}$ \\ Laura Monte Serrat Barbosa ${ }^{2}$ \\ Sonia Küster ${ }^{3}$ \\ Vanessa Pires ${ }^{4}$
}

\section{Resumo}

Este texto propõe uma reflexão sobre o processo de aprender e ensinar na atualidade e sobre o conhecimento como uma construção humana complexa que necessita ser reconstruído pelo aprendiz e não simplesmente reproduzido. Convida o leitor a percorrer as dimensões do sujeito cognoscente pensar, sentir, agir e interagir _ com a finalidade de estabelecer conexões entre elas, tanto no exencício de autoconhecimento de quem ensina como de quem aprende.

Palavras-chave: Aprendizagem; Conhecimento; Conexões; Autoconhecimento; Dimensões.

1 Pedagoga, Especialista em Psicopedagogia, Educação Especial e Grupos Operativos, Mestre e Doutora em Educação, Professora Titular da Área da Educação da PUCPR, Coordenadora do Curso de Especialização em Psicopedagogia da PUCPR. Endereço Eletrônico: evelisep@onda.com.br

2 Pedagoga, especialista em Psicologia Escolar e da Aprendizagem, Psicopedagogia e Teoria e Técnica de Grupos Operativos, Mestre em Educação. Endereço Eletrônico: lauraserrat@bol.com.br

3 Pedagoga, especialista em Psicopedagogia e Educação Infantil, Mestranda em Educação pela PUCPR, Psicopedagoga Clínica, Presidente da Associação Brasileira de Psicopedagogia seção Paraná Sul gestão 2005/2007. Endereço Eletrônico: soniakuster@uol.com.br

4 Psicóloga, especialista em Modalidades de Intervenção no Processo de Aprendizagem e Terapia Comportamental e Cognitiva, Psicóloga Clínica. Endereço Eletrônico: vanpires@click21.com.br 


\section{Abstract}

This text considers a reflection on the process to learn and to teach in the present time and on the knowledge as a construction complex human being who needs to be reconstructed by the apprentice and not simply reproduced. Cognoscente - to think, to feel, to actand to interact - with the purpose invites the reader to cover the dimensions of the citizen to establish connections between them, as much in the exercise of self-knowledge of who teaches as of who it leams.

Keywords: Learning, Knowledge, Connections, Self-knowledge, Dimensions.

\section{A motivação inicial}

No Programa de Pós-graduação em Educação da PUCPR, dentro da linha de pesquisa Teoria e Prática, existe um grupo de pesquisadores voltados ao estudo do processo de aprendizagem e do conhecimento, cujo projeto de pesquisa é Aprendizagem e Conhecimento na Formação Docente.

Este grupo de pesquisa é constituído por educadores preocupados com o desajuste crescente entre o que a sociedade, escola e família pretendem que os seus cidadãos, alunos e filhos aprendam e conheçam, e os processos necessários para que isso aconteça.

Um dos aspectos responsáveis por este desajuste está relacionado à formação dos educadores, fragmentada e utilitarista, que se reflete na sua forma de lidar com aprendizagem do outro e conseqüentemente com seu estilo de ensinar.

A dicotomia existente entre o desenvolvimento natural e o papel modelador do meio prevaleceu em quase todo o século $\mathrm{XX}$, o que interferiu sobremaneira na concepção de aprendizagem e na prática educativa.

O progresso tecnológico e a rapidez presente nas relações do ser humano com o mundo têm solicitado mudanças significativas na maneira de aprender.

Segundo Portilho (2005) “... o diálogo entre hereditariedade e ambiente, natureza e criação se manifesta, dando-nos a possibilidade de perceber que as diferenças entre as duas visões de aprendizagem levam-nos a descobrir sua convergência e, conseqüentemente encontrar uma outra maneira de considerar a mesma questão".

Foi esta idéia de convergência que nos levou a escolher a palavra conexão no processo de aprendizagem e conhecimento como o aspecto articulador de elementos que, até então, foram colocados como opostos.

Aprender hoje é diferente do que significava aprender no passado ainda próximo. Santos afirma: "Há um clima de perplexidade no ar e a sensa- 
ção de que se habita um intervalo do tempo, entre um presente quase terminado e um futuro ainda não nascido" (apud TESCAROLO, 2005, p. 27).

Aprender, na contemporaneidade, exige que usemos como expediente a seleção e a significação de conhecimentos dentre os milhares que fazem parte daqueles construídos pela história.

O educador diante dessa mudança paradigmática necessita fundamentar-se, avaliar-se como aprendiz e principalmente mudar seus esquemas de aprendizagem para poder posicionar-se de outra forma e acompanhar em sua práxis os desafios e a complexidade que o mundo demanda.

A segmentação do conhecimento privilegiada numa visão especialista de saber - abordagem analítica _ não é mais suficiente para promover um movimento de aprender e ensinar que leve o aprendiz a articular as diferentes áreas do conhecimento.

Segundo Morin (1996), o que sustenta esta concepção é o princípio de disjunção, por meio do qual é possível chegar-se a um catálogo de elementos desconectados que reduzem o ser humano à existência de um modelo fixo e rígido que anula a diversidade.

O que temos percebido é que este modelo não está preenchendo as necessidades do homem da contemporaneidade. Sendo assim, é premente que o ser humano supere a divisibilidade do conhecimento e da sua aplicabilidade. Quais são os limites do conhecimento?

Devemos conceber os limites biológicos, os limites cerebrais, os limites antropológicos, os limites sociológicos, os limites culturais de todo 0 conhecimento, o que nos permitirá ao mesmo tempo conhecer o nosso conhecimento, fazê-lo progredir em novos territórios e confrontar-nos com a indivisibilidade e indecidibilidade do real. Creio também que ela nos permitirá detectar melhor "as doenças", isto é, os fenômenos de esclerose ou de degenerescência que afeta os processos dos nossos pensamentos.[... ] ... compreender que conhecer é uma aventura incerta, frágil, difícil, trágica (MORIN, 1996, p. 32 e 33).

Conexões entre essas áreas se fazem necessárias na atualidade, sem descaracterizá-las, porém ampliando o olhar sobre o mundo e 0 aprendiz abordagem da complexidade sistêmica objeto de estudo de Tescarolo (2005) ao entender o conhecimento e a escola como um sistema complexo.

Ainda que complementares, todavia, os enfoques analítico e complexo se diferenciam de um modo fundamental: enquanto o primeiro propõe 0 conhecimento como um encadeamento de informações - conduzindo a uma redução dos saberes a um certo número de disciplinas insuficientemente conectadas e relativamente isoladas umas das outras, ainda que pretendendo 
uma perspectiva enciclopédica _, a abordagem da complexidade sistêmica interessa-se pelas interações dos elementos, prioriza percepção de totalidade e propõe o conhecimento como uma rede de significações, considerando suas dinâmicas de evolução e suas relações no tempo (p. 36).

O tema desta revista Conexões da Aprendizagem e do Conhecimento foi pensado em função da nossa crença de que relações se fazem necessárias para a superação dos descompassos existentes neste momento histórico que levam o ser humano a uma prática fragmentada e excludente na qual só é permitido ganhar e ganhar, saber e saber, poder e poder, ter e ter, sem admitir a diferença que, numa visão dialética, é o que possibilita o avanço e a transgressão.

\section{Conexões entre pensar, sentir, agir e interagir}

Como é possível, sem desconsiderar o já construído, superar as conseqüências de um modelo paradigmático tradicional na formação do aprendiz?

A primeira consideração a ser destacada frente a uma nova possibilidade de aprender diz respeito à concepção de totalidade e complexidade no que se refere ao aprendiz como um ser que pensa, sente, age e interage.

Para Silva (1998), o ser cognoscente, aquele que conhece e que aprende, é constituído por três importantes dimensões: racional, desiderativa e relacional. Ela diz que este é o verdadeiro objeto da Psicopedagogia e que deveria:

... considerar o ser humano como uma unidade de complexidade, ou seja, um ser pluridimensional com uma dimensão racional, uma dimensão afetiva/ desiderativa e uma dimensão relacional, esta última imolicando um aspecto contextual e um aspecto interpessoal. Este sujeito seria sujeito da construção do conhecimento e de sua própria autonomia e, ao mesmo tempo determinado pelas dimensões racional, desiderativa e relacional que o constituem ( $p$. 29-30).

A psicologia cognitiva, desde os meados dos anos cinqüenta, constatou que o conhecimento e a aprendizagem não acontecem somente pela razão vindo, desta forma, confirmar a existência destas dimensões.

A aprendizagem e o conhecimento, portanto, para acontecer, necessita de conexões entre essas dimensões, e entre elas e o contexto onde 0 sujeito está inserido. 


\section{A dimensão do pensar}

Vamos iniciar com a dimensão do pensar, pensando no mundo em que vivemos. Podemos até arriscar a dizer que, uma das capacidades de sobrevivência social contemporânea está no aprender a aprender. Existe um entusiasmo por parte dos teóricos e dos diferentes profissionais pela análise, desenvolvimento, criação, utilização e treinamento em habilidades e estratégias que venham melhorar os resultados e rendimentos das pessoas.

As pessoas, principalmente as que têm o desejo, são capazes não somente de aprender, senão de melhorar essa capacidade adquirindo estratégias para auto-regular seu próprio aprender. Igualmente existem aquelas que não apenas são capazes de pensar, senão de aprender a pensar usando estratégias cognitivas cuja seleção e aplicação devem ser autocontroladas. São pessoas que adquirem e desenvolvem estratégias metacognitivas, isto é, vão além da informação, conhecem o seu próprio conhecimento e aplicam esta postura na hora de aprender e pensar.

No entanto, a grande maioria das pessoas possui habilidades metacognitivas bem modestas, ou até mesmo pouco desenvolvidas, razão pela qual lhes custa um grande esforço aprender e pensar, sendo praticamente impossível melhorar seus rendimentos e resultados por si mesmas. Na verdade, não aprendemos ou não nos ensinaram a pensar em nossas possibilidades e limitações.

Aquele que ensina precisa ser convidado a conhecer-se como aprendiz, em todas as dimensões que o envolvem, para poder compreender a aprendizagem daquele que está na escola para aprender. Esse movimento/processo viabilizaria a modificação da sua modalidade de ensinar que repercute na aprendizagem do aluno.

É chegada a hora da escola posicionar-se, por meio de seus "ensinantes", primeiramente promovendo oportunidades para que cada um tome consciência da sua própria modalidade de aprendizagem. A partir desse movimento teriam controle sobre ela para que assim possam autofazer-se e buscar a transformação de suas modalidades de ensino.

Como conseqüência desta atitude, que integra consciência, controle e transformação, a escola pode interpretar e ressignificar as informações do momento histórico atual visando desenvolver variáveis metodológicas a serviço da diversidade de modalidades de aprendizagem.

Este movimento provoca no educador a necessidade de uma nova reflexão sobre o sujeito que pensa. Pogré, Lombardi e a Equipe do Colégio Sidarta (2006) reforçam esta idéia quando enfatizam que "... a aprendizagem para a compreensão implica comprometer-se com ações reflexivas, com desempenhos que constroem compreensão" (p. 10). Esta colocação deixa clara a 
idéia de que para pensar é necessário sentir, agir e interagir, é aprender na ação, no convívio.

Até agora o ensino privilegiou o pensamento analítico, lógico e linear, caracterizado pela aceitação incondicional daquilo que é ensinado, sem questionar a informação, sua validade ou pertinência. Atualmente a exigência é outra. Solicita-se um ensino que privilegie o pensamento independente, favorecendo o pensar, a reflexão, o sentido crítico e a ação diante dos diferentes conteúdos e informações, no qual o aluno possa distinguir entre o que é essencial e o acessório. Como diz Ontorria (2000): "No novo enfoque da aprendizagem se potencializa o pensamento divergente, que sintoniza com o processo criativo e com a diversidade de opções em relação à informação a ser adquirida e as estratégias que convêm utilizar, frente ao pensamento ... único" (p. 23).

Desta forma espera-se superar uma única maneira de se pensar a aprendizagem e o conhecimento, mas possibilitar ao sujeito que aprende pensar com autonomia, respeitando seu tempo e espaço, estabelecendo conexões com suas diferentes dimensões.

\section{A dimensão do sentir}

No entanto, sabemos que a aprendizagem não depende apenas do desenvolvimento da dimensão do pensar. Para aprender precisamos considerar o sujeito que sente.

Esta dimensão, chamada por Silva (1998) de dimensão afetiva/desiderativa, é que possibilita ao aprendiz o desenvolvimento do desejo de aprender.

O sujeito que aprende é constituído por um saber inconsciente, portanto desconhecido, que foi considerado, por Freud (apud SILVA 1998), a essência da vida mental. Apenas parte deste saber pode tornar-se consciente. Este sistema inconsciente, processo primário do pensamento é que possibilitará o desenvolvimento semiótico ou simbólico, desiderativo, e que funciona regendo o ser humano pelo princípio do prazer, do desejo.

O desejo implica na inacessibilidade de um objeto; caracteriza-se por ser a busca de um objeto perdido. A falta faz com que se busque a realização por meio de substitutos, que, no entanto, não a preenchem plenamente e mantêm o vazio. Desta forma o desejo se renova constantemente.

No processo de aprender é exatamente isto que acontece, temos um vazio, buscamos o conhecimento, mas não nos sentimos plenamente satisfeitos, pois aquele conhecimento que foi trazido ao consciente deixa outros vazios que implicam em novas buscas. 
O fato do ser cognoscente possuir um sistema inconsciente em sua vida mental faz com que ele não possa ser senhor absoluto de seus pensamentos.

O sistema consciente, secundário, funcionará regido pelo princípio da realidade e permitirá o desenvolvimento da lógica e da intelectualidade, mas não garantirá a certeza.

É importante ressaltar que inconsciente e consciente se relacionam e cooperam e que o inconsciente sendo um sistema de funcionamento não é um abismo onde o consciente deposita tudo o que lhe perturba. Assim sendo, a dimensão desiderativa é constituinte no processo de construção do conhecimento na medida em que o ser cognoscente é determinado por um saber inconsciente, instituído por moções do desejo (SILVA, 1998, p. 38).

A questão do desejo é, portanto, um elemento importante do processo de aprendizagem e envolve todas as outras dimensões do sujeito que aprende.

A aprendizagem acontece na interação do aprendiz com o seu contexto histórico, social, afetivo e com seus pares possibilitando, desta forma, uma construção intra e interpsíquica do conhecimento. $O$ aprendiz se constrói como sujeito cognoscente na medida em que constrói a realidade balizado por suas emoções e afetos.

O conhecimento, neste sentido, é o resultado da conexão das diferentes experiências vividas na área corporal, extracorporal e simbólica envolvida pela emoção.

Nesta perspectiva a construção do eu-sujeito acontecerá antes e concomitante à construção da realidade. Será a qualidade da vida afetiva da criança, ao longo dos primeiros anos de vida, que viabilizará suas aprendizagens. A temperatura do campo afetivo em que a criança viver será o propulsor das aprendizagens produzidas por ela. [...] Nessa afirmativa, está inserida a compreensão da aprendizagem como um movimento intimamente comprometido com o universo simbólico do aprendiz e com os seus conteúdos emocionais, e ainda, atrelados à realidade interna e externa de cada um. (PAROLN, 2005, p. 71-72)

A vinculação afetiva com as situações de aprendizagem possibilita a organização de estruturas de condutas que constroem práticas reflexivas e têm como resultado a aprendizagem significativa.

Entende-se, portanto, que para aprender, uma pessoa mobiliza todo um sistema, que está muito além de um processo de desenvolvimento motor e cognitivo, é, também, afetivo/emocional, fruto das relações familiares e sociais. 
A dimensão do sentir, portanto, precisa ser revalorizada nos espaços educativos e nas relações de aprendizagem.

Na articulação entre ensinar, aprender e conhecer, as conexões entre afeto, razão e relação devem fazer parte integrante dos esquemas conceptuais, procedimentais e atitudinais do professor de tal forma que isso se traduza no ambiente de sala de aula - na metodologia, nas avaliações, nos recursos e instrumentos didáticos, na organização do espaço, tempo e principalmente nas relações interpessoais.

\section{A dimensão do agir e do interagir}

Neste sentido faz-se necessário preocupar-nos, também, com o sujeito que age e interage.

O aprendiz é um ser social que necessita estar em constante interação com o meio para que possa desequilibrar-se, modificar-se, adequar-se, equilibrar-se, e conseqüentemente, aprender e conhecer.

É este movimento constante que possibilita com que o aprendiz construa vínculos afetivos e conhecimentos com os quais realizará operações sobre a realidade externa, provocando novos conflitos cognitivos, afetivos e sociais que 0 modificam e modificam o meio, promovendo recursos para intervir na realidade, tanto do ponto de vista teórico como prático.

Segundo Vygotsky (apud DEL RIO, 1996) o funcionamento do cérebro humano fundamenta-se na idéia de que as funções psicológicas superiores se constroem na relação que o sujeito estabelece com o mundo mediado pela cultura em que está inserido. Este processo acontece por meio da atividade prática e instrumental, em interação ou cooperação social, mediante a interatividade entre a criança e os outros - adultos ou companheiros de diversas idades - na zona de desenvolvimento proximal (idéia de mediação).

Uma operação que inicialmente representa uma atividade externa é reconstruída e começa a ocorrer intemamente; um processo interpessoal termina por transforma-se em outro interpessoal. No desenvolvimento cultural da criança, toda função aparece duas vezes: primeiro em nível social e, mais tarde, em âmbito individual: primeiro entre pessoas - interpsicológica - e depois, no interior da própria criança - intrapsicológica. [...]Todas as funções superiores se originam como relações entre seres humanos (p. 84-85).

A idéia de mediação refere-se à relação triangular entre o sujeito que aprende, o objeto de conhecimento e o outro - pais, professores, grupo social _, que propiciam condições para a criança representar dados do mundo real ao seu contexto intrapsíquico, agindo e interagindo ao aprender e conhecer. 
Portanto, para empregar conscientemente a mediação social, é relevante que se dê importância não apenas aos conteúdos e aos mediadores instrumentais (o que se ensina e com o quê), mas também aos agentes sociais (quem ensina) e suas peculiaridades.

Aprender e ensinar, nessa dimensão, só tem sentido se for para instrumentalizar, tanto o aprendiz quanto o ensinante, a conhecerem-se mais profundamente, objetivando a construção de uma sociedade mais crítica, voltada às questões da humanidade e da humanização.

Pensar uma situação de aprendizagem na qual alguém ensina e alguém aprende faz com que se coloque em questão, além dos aspectos ligados ao sujeito que pensa e ao sujeito que sente, duas premissas: a ação e a interação que ocorrem em um ambiente que deve ser mobilizador de aprendizagens, portanto um ambiente educativo.

O professor, ou "ensinante", como denomina Fernandez (1994) age de acordo com seus referenciais de vida, como "aprendente" aliado a concepções teóricas que auxiliem a construir sua modalidade de ensinar. Esta modalidade é colocada em prática na interação com o aluno o qual também apresenta, internalizadas, outras modalidades de ensino, assim como uma modalidade de aprendizagem construída na sua história, marcada pelas relações familiares, até chegar à instituição escolar.

Nesse sentido, como abordado anteriormente, aquele que ensina precisa ser convidado a conhecer-se como aprendiz.

As ações e interações do sujeito que aprende e ensina estão diretamente ligadas a sua histónia de vida, além do seu contexto social, ao vivido e aos "saberes de experiência" que fundamentarão seu processo de aprendizagem.

Scoz (2002, p. 92) salienta que "o resgate das histórias de vida e de aprendizagem dos professores pode elucidar quais significados eles construíram em relação aos processos de aprender e de ensinar e as modalidades de aprendizagem que construíram em reciprocidade às modalidade de seus ensinantes".

Tais modalidades de ensinar e aprender serão aqui entendidas como o conjunto de habilidades, estratégias e estilos colocados em funcionamento a partir de relações intra e interpsíquicas e construídas na interação com o meio, no decorrer da história do aprendiz e daquele que ensina.

Dentro desta dimensão do agir e interagir é importante se considerar o espaço coletivo, do grupo de aprendizes, como um espaço privilegiado para o estabelecimento de conexões de aprendizagem e conhecimento.

\section{Fazendo conexões ao concluir}

A sociedade atual, apesar das mudanças de paradigmas e do avanço da reflexão sobre novas possibilidades de aprendizagem e conhecimento, ain- 
da é regida pelo modelo do conhecimento único e da certeza. Neste sentido, a escola também continua utilizando este modelo como referencial de ensino e aprendizagem, mostrando a existência de um vácuo entre o discurso e a prática educativa. Sendo assim, as informações não são transformadas em conhecimento. Continuam sendo propriedade de quem as traz, sem nenhuma surpresa e deixam para ao aprendiz somente o espaço para reproduzi-las.

O inesperado, no entanto, é o pulsar da aprendizagem e conhecimento. Temos que entrar e sair das folhas dos livros e apostilas, ousando viver a diferença, as não verdades, a provisoriedade, a complexidade, o desconhecido percebendo-os como aliados e não como uma ameaça.

É eminente a necessidade de uma formação contínua do ensinante que foque o conhecimento da própria aprendizagem e possibilite que ele se pense, se aproprie deste seu processo de aprender para poder fazer conexões e modificar sua forma de ensinar.

Esta formação precisa que o(a) professor(a) deseje disponibilizar-se para autofazer-se como aprendiz e como ensinante, porém sem considerá-lo como o único responsável pelas dificuldades relativas à aprendizagem e ao conhecimento no interior da escola.

$\mathrm{O}$ que se percebeu, em alguns momentos desta pesquisa, é que o(a) professor(a) necessita, pela falta de autoconhecimento, reafirmar sua autoridade diante do \(a) aluno(a) de forma autoritária, sem considerar o movimento das relações. Parece existir um receio de perder o respeito que lhe cabe como profissional e ser humano.

Ao desvendar e apropriar-se de suas conexões de aprendizagem e conhecimento, o(a) professor(a) pode encontrar a segurança necessária para ser respeitado no seu papel de profissional e respeitar o processo de aprendizagem e de construção de conhecimento do outro.

\title{
A Paixão de Conhecer
}

Madalena Freire

\author{
Eu não sou você \\ Você não é eu. \\ Mas sei muito de mim \\ Vivendo com você. \\ E você, sabe muito de você vivendo comigo? \\ Eu não sou você \\ Você não é eu. \\ Mas encontrei comigo e me vi \\ Enquanto olhava pra você
}


Na sua, minha, insegurança

Na sua, minha, desconfiança

Na sua, minha, competição

Na sua, minha, birra infantil

Na sua, minha, omissão

Na sua, minha, firmeza

Na sua, minha, impaciência

Na sua, minha, prepotência

Na sua, minha, fragilidade doce

Na sua, minha, mudez aterrorizada

E você se encontrou e se viu, enquanto

Olhava pra mim?

Eu não sou você

Você não é eu.

Mas foi vivendo minha solidão

Que conversei com você

E você, conversou comigo na sua solidão

Ou fugiu dela, de mim e de você?

Eu não sou você

Você não é eu.

Mas sou mais eu, quando consigo

Lhe ver, porque você me reflete

No que eu ainda não sou

No que já sou e

No que quero vir a ser ...

Eu não sou você

Você não é eu.

Mas somos um grupo, enquanto

Somos capazes de, diferenciadamente,

Eu ser eu, vivendo com você e

Você ser você, vivendo comigo.

\section{Referências}

COLL, César, PALÁCIOS, Jesús, MARCHESI, Álvaro (org.). Desenvolvimento Psicológico e Educação (vol. 2). In: Del Rio, Amélia. Educação e desenvolvimento: a Teoria de Vygotsky e a zona de desenvolvimento próximo. Porto Alegre: Artes Médicas, 1996. 
FREIRE, Madalena. O que é um grupo? In: Grossi, E; Bordin, J. (org.). A paixão de aprender. Petrópolis: Vozes, 1992, p. 59-68.

MORIN, Edgar. O problema epistemológico da complexidade. Portugal: Europa-América, 1996.

ONTORRIA, Antonio, Gómez, Juan, Rubio, Ana Molina. Potenciar lacapacidad de aprender y pensar. Madrid: Narcea, 2000.

PAROLIN, Isabel. Professores formadores: a relação entre a família, a escola e a aprendizagem. Curitiba: Positivo, 2005.

POGRÉ, Paula; LOMBARDI, Graciela; Equipe Colégio Sidarta. 0 ensino para a compreensão: a importância da reflexão e da ação no processo de ensinoaprendizagem. Vila Velha: Hoper, 2006.

PORTILHO, Evelise Maria Labatut. Texto trabalhado na disciplina Aprendizagem e Conhecimento, do Curso de Mestrado em Educação da PUCPR. Como mudar para aprender e como aprender para mudar, 2005.

SCOZ, Beatriz (org.). (Por) uma educação com alma. Petrópolis: Vozes, 2000.

SILVA, Maria Cecília A. Psicopedagogia: em busca de uma fundamentação teórica. Rio de Janeiro (RJ): Nova Fronteira, 1998.

TESCARO LO, Ricardo. A escola como sistema complexo. São Paulo, (SP): Escrituras, 2005. 